Conclusion A swift response, using a range of case finding and health promotion strategies successfully curtailed a nascent outbreak of infectious syphilis among university students. An intensive approach to PN, with an emphasis on provider referral, ensured the majority of partners attended with minimal delay.

\section{P078 CLOSING THE AUDIT CYCLE IN THE MANAGEMENT OF PELVIC INFLAMMATORY DISEASE (PID): UPDATING TRUST GUIDELINES LEADS TO A HUGE IMPROVEMENT IN PID TREATMENT}

Elizabeth Williams, Manori Bandara, Maryam Ahmad, Jake Bayley*, Liat Sarner. Barts Health NHS Trust, London, UK

\subsection{6/sextrans-2016-052718.132}

Background Correct management of Pelvic Inflammatory Disease (PID) is important to reduce complications but often varies widely. An audit of PID management in our trust's GUM clinics was undertaken in 2014 which led to trust guidelines being updated in early 2015. The main finding was antibiotic regimes were varied; only $12 \%$ received a BASHH recommended regime. We re-audited the management of PID in 2015.

Aim To compare PID management across our trust's GUM clinics in 2014 and 2015.

Methods Electronic patient records of 141 female patients with C5A codes in 2014 and 100 in 2015 were reviewed and compared.

Results In both audits 98\% of patients had Chlamydia/Gonorrhoea NAATs sent; 93\% had vaginal microscopy in 2014 and $92 \%$ in 2015 , but cervical microscopy improved from $13 \%$ in 2014 to $45 \%$ in 2015 . Pregnancy tests were inconsistently done, $83 \%$ in 2014 and $75 \%$ in 2015 . Those with chlamydia, gonorrhoea or trichomonas vaginalis increased from $8 \%$ to $13 \%$ but bacterial vaginosis was the most common finding, 28\% in 2014 and $46 \%$ in 2015. Antibiotic regimes were BASHH recommended in 12\% (2014) and 88\% (2015), due to updated 2015 trust guidelines being in line with BASHH.

Discussion Improvements have occurred since 2014 but cervical microscopy and pregnancy tests are still not consistently being done. Low levels of STIs detected may represent incorrect diagnosis in some. Antibiotic prescription has improved significantly, however we are still below the BASHH target of 95\% (currently $88 \%$ compliance). We will re-present findings of this re-audit to clinics to improve standardisation of PID management.

\section{P079 HIV SERVICES IN A CHANGING PROVIDER LANDSCAPE: PATIENT EXPERIENCES AND PERCEIVED NEEDS}

${ }^{1}$ Nalin Hettiarachchi ${ }^{*}$, ${ }^{1}$ Kurian Vithayathil, ${ }^{1}$ Duncan Leverton, ${ }^{1}$ Ruth Sim, ${ }^{1}$ John Beale, ${ }^{2}$ Usharani Natarajan, ${ }^{1}$ Shalini Andrews. ${ }^{1}$ Buryfields Clinic, Guildford, UK; ${ }^{2}$ Earnsdale Clinic, Redhill, UK

\subsection{6/sextrans-2016-052718.133}

Background/introduction With recent commissioning changes, non NHS providers are increasingly being awarded contracts to manage services including HIV care. There is little data on patient views and experiences around this change.

Aim(s)/objectives To obtain service user view of the aspects of the HIV service which they consider important in the landscape of commissioning changes.

Methods A patient survey was carried out in a community-based HIV service managed by a non-NHS provider. Questions were created to cover the most affected areas of the service due to the changes of HIV service provision.

Results A representative sample of 44 attenders over 2 months undertook the survey; 34 men and 10 women. All were satisfied with the service. However some expressed concerns since change of provider, such as "services are being stripped off", "not enough staff", "standards have fallen", "staff are under severe stress". The proportion that rated the following aspects of the service as very important or important to patients are as follows: 24hour on-call service (98\%), clinician access to investigation (95\%), HIV team involvement in teaching wider NHS (98\%) and current location (95\%), HIV team involvement in their inpatient care (98\%) and co-location of HIV and Sexual Health service $(100 \%)$. The majority $(86 \%)$ wanted an NHS provider, while $7 \%$ had no preference.

Discussion/conclusion The majority of patients preferred an NHS provider, with co-located Sexual Health services. They rated links with acute trust and the wider NHS as important aspects of their care. This needs to be considered while commissioning, planning and delivering future services.

\section{P080 AUDIT OF THE MANAGEMENT OF SEXUAL ASSAULT COMPLAINANTS ATTENDING GENITOURINARY MEDICINE AGAINST THE BRITISH ASSOCIATION FOR SEXUAL HEALTH AND HIV UK NATIONAL GUIDELINES ON THE MANAGEMENT OF ADULT AND ADOLESCENT COMPLAINANTS OF SEXUAL ASSAULT 2011}

${ }^{3}$ Hayley Colton, ${ }^{2}$ Gemma Carr, ${ }^{1}$ Anna Garner*. ${ }^{1}$ Stockport NHS Foundation Trust, Stockport, UK; ${ }^{2}$ The Rotherham NHS Foundation Trust, Rotherham, UK; ${ }^{3}$ Sheffield Teaching Hospitals NHS Foundation Trust, Sheffield, UK

\subsection{6/sextrans-2016-052718.134}

Background/introduction Patients attending clinic following an alleged sexual assault (SA) involve a complex history and management plan. The regional Sexual Assault Referral Centre (SARC) is on site and so the clinic receives significant numbers of SA referrals. As a clinic we felt that the proforma for documenting such histories was not fit for purpose.

Aim(s)/objectives To compare the documentation and management of SA complainants against standards set out by The British Association for Sexual Health and HIV UK National Guidelines on the Management of Adult and Adolescent Complainants of Sexual Assault 2011.

Methods A retrospective case note review of notes coded for SA between $1 / 1 / 13$ and $31 / 3 / 14$. 36 case notes were identified for inclusion.

Results 32/36 patients were female, 29/36 were heterosexual. 30/36 were of white British origin. 26/36 were referred from the local SARC. Age range 13-79 yrs. Areas which performed well in relation to the auditable outcomes were documentation in relation to: when the assault took place $(100 \%)$, child protection needs $(100 \%)$, who the assailant was $(94 \%)$, if baseline testing occurred (94\%), follow up advice (91\%), what type of assault (87\%). Areas which performed less well included documentation in relation to: bleeding at time of assault (8\%), physical injuries $(12.5 \%)$, ejaculation (24\%), self harm (16\%), mental state assessment (33\%).

Discussion/conclusion Documentation of a number of standards requires significant improvement. Safeguarding was well managed, particularly in those under 18. As a result of gaps in documentation a SA proforma has been devised to capture all the detailed information required when assessing SA patients. 